\title{
A PRODUÇÃO ACADÊMICA SOBRE COMPETÊNCIAS: ASPECTOS GERAIS, METODOLÓGICOS E PRINCIPAIS ABORDAGENS TEMÁTICAS
}

\author{
Juliana Ferreira Bispo \\ Egressa do Instituto Federal de Educação Ciência e Tecnologia de Rondônia - IFRO \\ Brasil \\ Hígor Cordeiro de Souza \\ Instituto Federal de Educação Ciência e Tecnologia de Rondônia - IFRO \\ Brasil \\ Aloir Pedruzzi Junior \\ Instituto Federal de Educação Ciência e Tecnologia de Rondônia - IFRO \\ Denise Ton Tiussi \\ Instituto Federal de Educação Ciência e Tecnologia de Rondônia - IFRO
}

Data de submissão: 31/05/2017

Data de aceite: 05/02/2018

\begin{abstract}
RESUMO
O objetivo do presente artigo foi analisar artigos científicos publicados de 2008 à 2014 na biblioteca virtual SCIELO, a amostra foi composta por 56 artigos, o critério de seleção buscou por artigos que trabalhassem o tema competências no referencial teórico, nas palavras-chaves ou em alguma parte conclusiva. Através da análise dos autores e das abordagens temáticas o estudo visou identificar os perfis profissionais e acadêmicos dos pesquisadores além de identificar as correntes temáticas utilizadas nos textos sobre competências. O método utilizado no estudo foi o quanti-qualitativo e como resultados o estudo evidencia as principais temáticas que foram abordadas nos artigos com destaque para a denominada "área acadêmica" e "competências gerenciais".
\end{abstract}

Palavras Chaves: Competências. Estratégia. Organizações.

\section{ABSTRACT}

The objective of this article was to analyze scientific articles published from 2008 to 2014 in the SCIELO virtual library, the sample was composed by 56 articles, the selection criterion searched for articles that worked on the topic competences in the theoretical reference, keywords or In some conclusive part. Through the analysis of the authors and the thematic approaches the study aimed to identify the professional and academic profiles of the researchers as well as to identify the thematic currents used in the texts on competencies. The method used in the study was quanti-qualitative and as results the study highlights the main themes that were addressed in the articles with emphasis on the so-called "academic area" and "managerial competencies".

Keywords: Competencies. Strategies. Organizations. 


\section{INTRODUÇÃO}

Atualmente vivenciam-se constantes mudanças no cotidiano das pessoas e consequentemente nas organizações. Adequar-se e sobreviver a esses processos de transformação surge como o novo desafio a ser enfrentado nas organizações. Tais transformações exigem uma mudança na capacidade de planejamento estratégico que atua dentro das organizações, passando a ter um olhar mais amplo para os possíveis recursos fora do âmbito organizacional.

Diante da necessidade de adaptação ao ambiente externo as organizações passaram a considerar as influências que os elementos internos e externos possuem dentro do ambiente organizacional, que se encontra em constante mutação. Nessa mesma linha de raciocínio, para Dutra (2004) os constantes processos de globalização levaram as organizações a tomarem decisões de forma mais rápida com relação às situações enfrentadas.

Frente aos desafios atuais, as organizações, buscando novas estratégias como elemento de sustentabilidade, voltou seus olhos para as pessoas e demais elementos que compõem o ambiente. Esses recursos quando se referem às pessoas resumem-se a seus aspectos físicos e psicológicos, ou seja, suas capacidades de realizarem algo. Essas capacidades estabelecem competências únicas e de difícil imitação que cada organização possui, servindo como um diferencial competitivo em relação aos demais concorrentes. Através disso observamos a importância e a abrangência de competências como um pilar primordial, dando às organizações melhores recursos para criarem a própria estratégia.

Considerada como fator estratégico diferencial, as "competências" são assunto recorrente em diversas pesquisas científicas. Na Scientific Electronic Libary Online, biblioteca científica eletrônica (SCIELO), nos últimos 7 anos, de 2008 à 2014, foram publicados cerca de 776 artigos científicos referentes ao tema Competências, suas diversas áreas temáticas o que significa haver um grande interesse por parte dos pesquisadores sobre o tema.

Considerando as crescentes discussões sobre competências, principalmente, nos ambientes organizacionais e científicos, a presente pesquisa visa analisar a produção científica dos artigos relacionados a este tema. Assim, a fim de guiar a discussão, o trabalho traz a seguinte indagação: Quais os perfis profissionais dos autores, características metodológicas de seus artigos e atuais abordagens sobre Competências entre 2008 e 2014? 
O trabalho objetivou, analisar as características dos perfis profissionais dos autores, as metodológicas empregadas e principais abordagens temáticas dos artigos sobre o tema Competências entre 2008 e 2014. Utilizando como base de dados a plataforma SCIELO, foi realizado um estudo bibliométrico. Acredita-se que este tipo de análise pode trazer contribuição aos estudos científicos, através de levantamentos de dados, favorecendo possíveis análises sobre os artigos, a fim de favorecer a reflexão de como o tema está sendo abordado e desenvolvido nas publicações científicas.

\section{FUNDAMENTAÇÃO TEÓRICA}

No passado, o termo "Competência" era considerado apenas como um "reconhecimento" ou "autorização" para realizar determinado ato por mais que o praticante não tivesse o conhecimento necessário.

No fim da Idade Média, a expressão competência era associada essencialmente à linguagem jurídica. Competência dizia respeito à faculdade atribuída a alguém ou a uma instituição para apreciar e julgar certas questões. Os juristas declaravam que determinada corte ou indivíduo era competente para um dado julgamento ou para realizar certo ato. Por extensão, o termo veio a designar o reconhecimento social sobre a capacidade de alguém pronunciar-se a respeito de determinado assunto. Mais tarde, o conceito de competência passou a ser utilizado de forma mais genérica, para qualificar o indivíduo capaz de realizar determinado trabalho (ISAMBERTJAMATI, 1997).

Portanto, no decorrer dos anos, 'competência' passou de uma simples autorização e para o conceito de qualificação, algo que realmente representava a capacidade das pessoas, dando a elas potencial para realização dos atos. Segundo Brandão (2005), competência refere-se ao conjunto de conhecimentos e habilidades que qualifica um profissional, dando a ele competência, ou seja, capacidade para exercer determinada função.

Durante essa época histórica, ocorreram diversas guerras, cujos vencedores necessitavam de estratégias diferenciadas para ganhar de seus inimigos e a elaboração dessas estratégias necessitava de uma visão diferenciada do inimigo, ou seja, um recurso único, uma competência que fosse capaz de contribuir com a estratégia que era crucial durante a competitividade.

Assim como os países que guerreavam e ainda guerreiam em busca de territórios e poder, as organizações em geral também lutam para a conquista de seu espaço. Porém, não é suficiente vencer uma batalha, mas várias, para garantir a sustentabilidade da organização no ambiente competitivo, assim como afirma Moura e Bitencourt (2004) “as contínuas mudanças 
no cenário competitivo motivam a busca de novas estratégias por parte da empresa, para garantir a sua permanência no mercado".

Os acelerados processos de globalização têm ocasionado um aumento da competitividade entre as organizações. As instituições buscam meios novos (competências) para superar tais pressões e se manterem no mercado, assim passou-se a desenvolver conhecimentos novos adequados às estruturas.

Segundo Porter (1996) as escolhas de posicionamento requerem a definição de quais atividades a empresa desempenhará e como elas estarão relacionadas entre si. Seria uma concepção de como os elementos internos e externos da organização (competências) têm influência dentro da mesma, interferindo, portanto, na estratégia e no posicionamento competitivo.

A competitividade de uma organização seria determinada pela inter-relação dinâmica entre as competências organizacionais e a estratégia competitiva. [...] A implantação da estratégia gera novas configurações de recursos e novas competências que, por sua vez, irão influenciar novamente a formulação da estratégia. (FLEURY; FLEURY, 2004)

De acordo com Porter (1996), "uma alternativa é buscar extensões da estratégia que alavanquem o sistema de atividades existentes de maneira a criar serviços ou especificações que os rivais considerem ser impossível combater em bases individuais". Esses "serviços" ou "especificações" seriam competências únicas difíceis de serem imitadas que, consequentemente, diferem uma organização das demais, dando a ela uma maior vantagem competitiva. Prahalad e Hamel (1995) caracterizam o conjunto de habilidades e tecnologias de um negócio como suas competências por proporcionar as vantagens que a empresa utiliza para competir, constituindo o recurso mais valioso da organização.

As reais fontes de vantagem devem ser encontradas na capacidade da gerência em consolidar tecnologias em âmbito corporativo e nas habilidades de produção em competências que empoderem negócios individuais para se adaptarem rapidamente às oportunidades em mudança. (PRAHALAD; HAMEL, 1990)

Porter (1996) e Drucker (1999) afirmam que as competências organizacionais fazem parte da personalidade de cada organização e as diferenciam das demais gerando vantagem competitiva. Tendo em vista as argumentações acima expostas, é razoável afirmar que o conhecimento que uma organização deve ter de suas competências é crucial para que haja uma diferenciação que consequentemente gere vantagem competitiva.

\subsection{COMPETÊNCIAS ORGANIZACIONAIS E INDIVIDUAIS}

Prahalad e Hamel (1990) construíram uma corrente de pensamento em relação ao que caracterizam como "competências essenciais", para os autores competência seria a capacidade 
de combinar, misturar e integrar recursos disponíveis para criação de serviços ou produtos. Os autores ainda diferenciam as competências organizacionais das essenciais: as competências essenciais seriam aquelas que obedecem a três critérios: oferecem reais benefícios aos consumidores, são difíceis de imitar e dão acesso a diferentes mercados. Ao definir sua estratégia competitiva a empresa identifica as competências essenciais do negócio e as competências necessárias a cada função - as competências organizacionais.

De acordo com Fleury e Fleury (2003), o conceito desenvolvido por Prahalad e Hamel (1990) define que competências essenciais são recursos intangíveis, ou seja, que não podem ser medidos ou tocados, caracterizados como: recursos difíceis de serem imitados; recursos que necessitam da relação mercado e cliente para que empresa possa promover produtos/serviços diferenciados e que atendam as demandas e necessidades de tais clientes; recursos que quando gerenciados e utilizados permitem uma maior flexibilidade da organização possibilitando maior atuação em diversos campos.

Prahalad e Hamel (1998) caracterizam competências essenciais como algo mais amplo do que apenas competências de cada função da organização, sendo um aprendizado geral coordenando e integrando as diversas habilidades e recursos que a organização possui ou tem acesso. Ainda segundo os autores pode-se fazer uma comparação entre uma organização e uma árvore que cresce a partir de suas raízes. As competências são as raízes da corporação, os produtos e serviços seriam os frutos e folhas, as raízes são as fontes ocultas do crescimento das árvores e oferecem à organização alimento, sustentação e estabilidade.

No que concerne às competências individuais Fleury e Fleury (2001, p. 188) afirmam que são "um saber agir responsável e reconhecido que implica mobilizar, integrar, transferir conhecimentos, recursos e habilidades que agreguem valor econômico à organização e valor social ao indivíduo".

Fleury e Fleury (2001, p. 183) também afirmam que o tema competência está “associado a diferentes instâncias de compreensão: no nível da pessoa (competência do indivíduo), das organizações (competências organizacionais) e dos países (sistemas educacionais e formação de competências)".

De acordo com Prahalad e Hamel (1990) uma empresa não deve ser vista só como um portfólio de produtos e serviços, mas também como um portfólio de competências. Sendo as competências o conjunto de conhecimentos, habilidades e comportamentos que possibilitam o desenvolvimento, disseminação e a aplicação de novas tecnologias e capacidades essenciais ao sucesso da empresa. 


\subsection{COMPETÊNCIAS COMO GERENCIAMENTO DE RECURSOS}

Os recursos que a organização possui determinam quais são as competências a serem construídas. São exigidas competências certas para a utilização eficiente dos recursos que uma organização tem acesso, sejam eles encontrados no ambiente interno ou externo.

Um recurso é algo que a organização possui ou tem acesso, mesmo que esse acesso seja temporário [...] uma competência é uma habilidade para fazer alguma coisa [...] uma competência é construída a partir de um conjunto de 'blocos' denominados recursos (Mills et al., 2002, p. 9-14)

Para Zarifian (2001) a competência é a colocação de recursos em ação em uma situação prática. Não somente aqueles recursos que possuímos ou adquirimos, mas aqueles que sabemos como colocar em ação. É uma inteligência prática das situações que, apoiandose em conhecimentos adquiridos transforma-os á medida que a diversidade das situações aumenta. A competência é a iniciativa sob a condição de autonomia, que supõe a mobilização de dois tipos de recursos: os recursos internos pessoais (adquiridos, solicitados e desenvolvidos pelos indivíduos em dada situação) e os coletivos (trazidos e colocados à disposição pelas organizações). É a possibilidade de mobilizar redes de atores em volta das mesmas situações, de compartilhar desafios e de assumir respectivas áreas de responsabilidade.

Segundo Fleury, Fleury (2004) a utilização de recursos ocasiona a formação de um círculo entre a formulação de estratégia e a formação de competências. As competências são formadas a partir da utilização de recursos e as estratégias são elaboradas a partir de quais recursos estão disponíveis, resultando em competências essenciais.

\section{METODOLOGIA}

A presente pesquisa se caracteriza como quali-quanti. A escolha do método qualiquantitativo foi em função da abrangência que esse modelo proporciona nos resultados do estudo. De acordo com Silva (2011) “[...] em pesquisas qualitativas o importante é o que se fala sobre um tema, enquanto que em pesquisas quantitativas o importante é quantas vezes é falado [...] Uma não substitui a outra: elas se complementam".

O artigo também apresenta aspecto descritivo. Segundo Gil (2002), As pesquisas descritivas têm como objetivo a descrição das características de determinada população ou fenômeno e o estabelecimento de relações entre as variáveis. 
Como base de dados foi selecionada a plataforma de trabalhos acadêmicos Scientific Eletronic Library Online (SCIELO), devido o seu grande reconhecimento na área acadêmica e por conter publicações das mais importantes e variadas revistas científicas da área de gestão. A amostra foi delimitada pela busca de artigos a partir do termo 'Competências' e filtrados pelas seguintes áreas temáticas: Gerenciamento, Administração Pública e Ciências Sociais Aplicadas. Foram selecionados inicialmente 84 artigos científicos, dos quais 17, após leitura, foram excluídos, resultando em uma amostra real de 56 artigos científicos. A exclusão dos 17 artigos ocorreu em função de não se referenciarem de forma específica ao tema “competências", ou ainda por serem artigos repetidos.

Para a análise dos artigos da amostra foi construído um roteiro com os itens descritos a seguir: (a) aspectos gerais dos artigos: ano, local e revista de publicação e informações sobre os autores (instituição de ensino, formação profissional, atuação profissional e área de formação); (b) aspectos específicos dos artigos: tipo de metodologia (qualitativo, quantitativo ou misto, objetivos, procedimentos metodológicos e técnicos, instrumentos e público alvo das coletas de dados) e (c ) categorização de acordo com as abordagens temáticas mais recorrentes a saber: Inovação; Visão Baseada em Recursos (VBR); Liderança; Gestão por Competências (GPC) e Competências Gerenciais; Aprendizagem Organizacional e Desenvolvimento de Competências; Internacionalização e Competências Interculturais; Competências dos trabalhadores; Área acadêmica; Competências individuais e organizacionais. Os dados levantados foram formatados em planilhas eletrônicas e ao final foram feitas as análises por meio de estatística descritiva simples e conforme a interpretação dos pesquisadores sobre os dados.

\section{ANÁLISE DOS RESULTADOS}

\subsection{PERFIL DOS AUTORES}

Antes de tratarmos sobre as pesquisas, é importante termos uma noção de qual é o perfil geral de seus autores, que possuem interessam pelo tema como mostra, por exemplo, a figura 1, o qual trata das principais universidades presente na formação dos autores. 
Figura 1 - Instituição de Ensino dos Autores dos Artigos Analisados de 2008 a 2014



Fonte: dados da pesquisa.

Podemos perceber a maior aparição da Universidade de São Paulo (USP) na formação dos pesquisadores científicos seguida da Universidade de Brasília (UnB) e Fundação Getúlio Vargas (FGV). Na sequencia temos; Universidade Federal do Rio Grande do Sul (UFRGS); Universidade Federal de Minas Gerais (UFMG); Pontifícia Universidade Católica (PUC); Universidade Federal do Paraná (UFPR) e Universidade Federal de Santa Catarina (UFSC), Universidade Presbiteriana Mackenzie. Houve ainda a presença de 14 instituições estrangeiras na formação profissional dos autores, das seguintes nações: Portugal, França, Bélgica, Estados Unidos da América e Canadá, totalizando 11\% do número total de autores. Das 5 primeiras instituições que mais publicaram sobre competências vale o destaque de que apenas uma é particular (FGV), sendo o restante todas instituição de ensino público e gratuito. O gráfico a seguir mostra a porcentagem dos níveis de formação dos autores com relação ao número total de autores que foi 148 . 


\section{Figura 2 - Formação Acadêmica/Profissional}

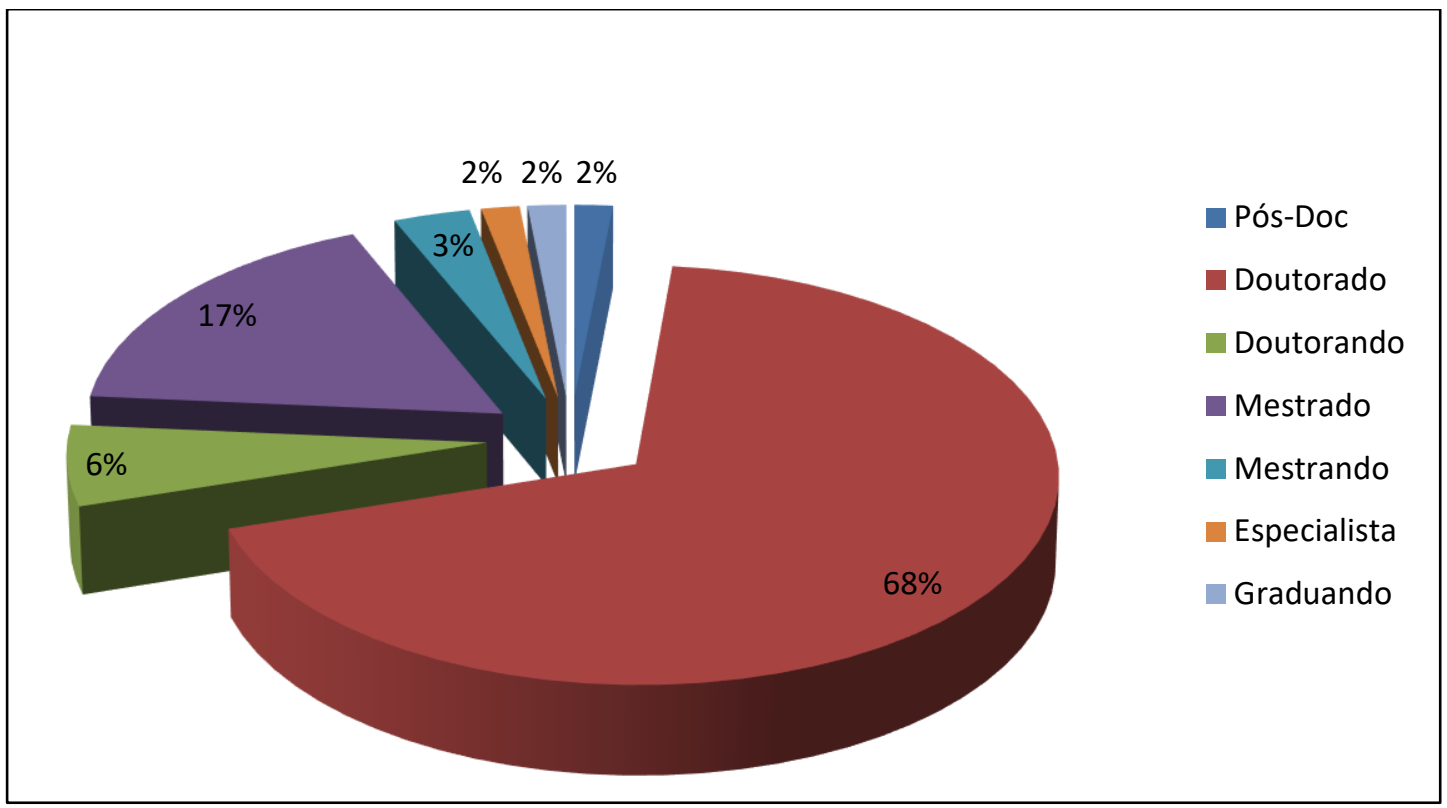

Fonte: dados da pesquisa.

As intervenções nas pesquisas científicas vêm não apenas dos níveis mais altos de formação acadêmica, mas também dos níveis consideramos mais "inferiores", conforme o gráfico $68 \%$ dos pesquisadores são doutores , entretanto é válido salientar que Kuark, Manhães e Medeiros (2010) afirmam que "É um mito que a ciência é apenas para aqueles com doutorado. Se se aceita a existência de níveis de pesquisa ou fases de pesquisa, podem investigar tanto estudantes de graduação como de pós-graduação". A tabela 3 mostra a quantidade e porcentagem das atuações profissionais dos autores, é válido lembrar que cada artigo pode conter entre 1 (um) até 5 (cinco) autores.

Tabela 1 - Atuação Profissional dos Autores

\begin{tabular}{ccc}
\hline Atuação & Quantidade & Porcentagem \\
\hline Professor & 96 & $64,86 \%$ \\
Analista & 4 & $2,7 \%$ \\
Gerente & 3 & $2,02 \%$ \\
Pesquisador & 3 & $2,02 \%$ \\
Perito Criminal & 1 & $0,67 \%$ \\
Outros & 3 & $2,02 \%$ \\
Não identificado & 38 & $25,67 \%$ \\
\hline
\end{tabular}

Fonte: dados da pesquisa.

Há uma prevalência significativa de professores no comando e coordenação dos artigos, retratando a ideia de que essa é uma atividade extremamente voltada para o círculo acadêmico. 
Dedicação à pesquisa científica é uma das ações mais importantes para as universidades. A ciência, no ambiente acadêmico, pode e deve ser abordada em profundidade. Isto deve ser entendido sempre no sentido do ensino das ciências e da dedicação à pesquisa científica como uma fonte de renovação e de exigência de progresso. (KUARK; MANHÃES e MEDEIROS, 2010, p. 08)

Houve maior prevalência da área de Administração entre os pesquisadores, somando 47,29\% do total da amostra. Entretanto diversas outras de formação foram identificadas entre os pesquisadores, a saber: a psicologia, que faz parte do currículo de $12,16 \%$ dos autores pesquisados; Engenharia de Produção, presentes em 7,43\%, Contabilidade com 2,70\%, Gestão e Educação com 2,02\% cada um, e outros correspondendo a 6,08\% que abrangem áreas como sociologia, letras, economia, comunicação, relações humanas e sistemas. Em cerca de $20 \%$ dos pesquisados não foi possível se verificar com exatidão sua área de formação.

\subsection{ASPECTOS METODOLÓGICOS}

Neste tópico serão feitas as classificações dos artigos quanto a sua metodologia, instrumentos e público-alvo, que foram utilizados para coleta de dados e as abordagens temáticas. No gráfico a seguir, tem-se a porcentagem dos métodos utilizados pelos autores nas suas respectivas pesquisas.

\section{Figura 3 - Metodologia da Abordagem do Problema}

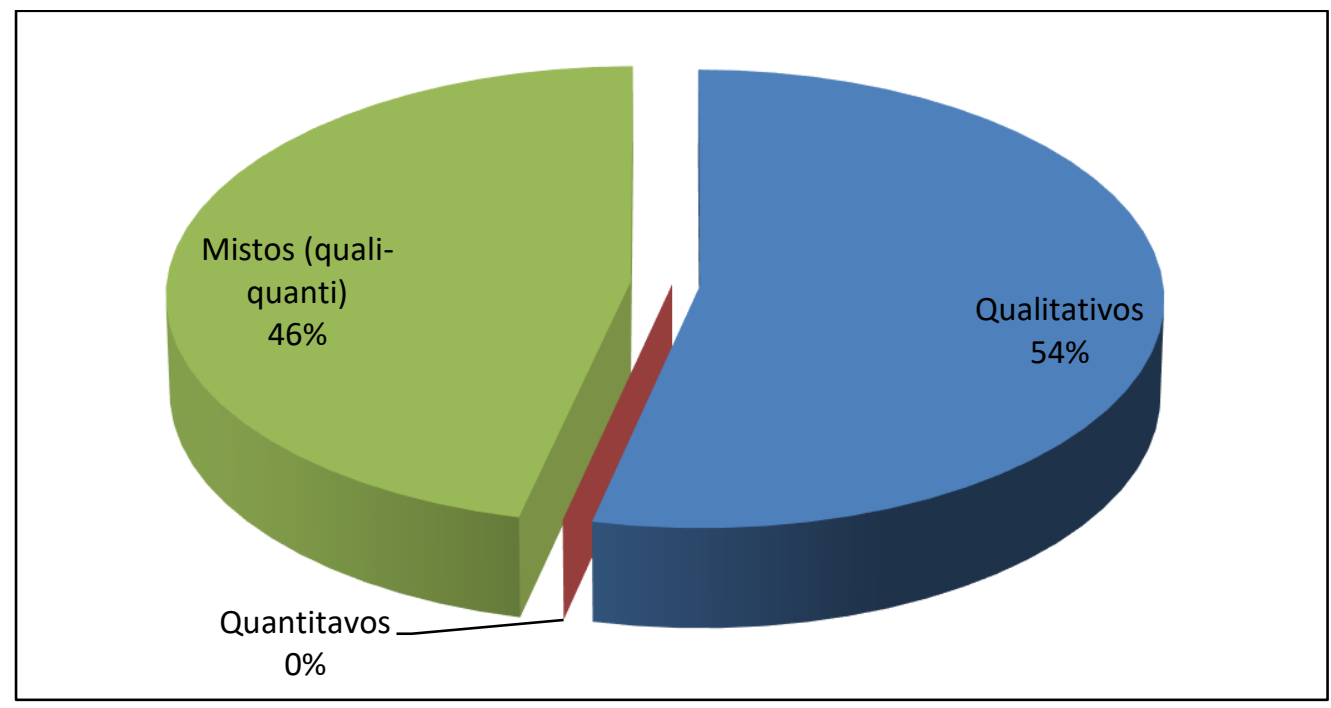

Fonte: dados da pesquisa. 
Conforme se pode constatar houve equilíbrio entre as abordagens qualitativa e de métodos mistos, em nenhum dos casos foi verificado um artigo com características metodológica puramente quantitativas.

A porcentagem significativa de artigos que integram os dois tipos de abordagens pode ser explicada pelo fato do aspecto qualitativo se referir a uma observação mais subjetiva, e a quantitativa quando o objeto ou objetivo do estudo puder ser "delimitado e mensurável". O gráfico a seguir traz as classificações dos estudos de acordo com os objetivos das pesquisas.

\section{Figura 4 - Classificação Quanto aos Objetivos das Pesquisas Científicas}

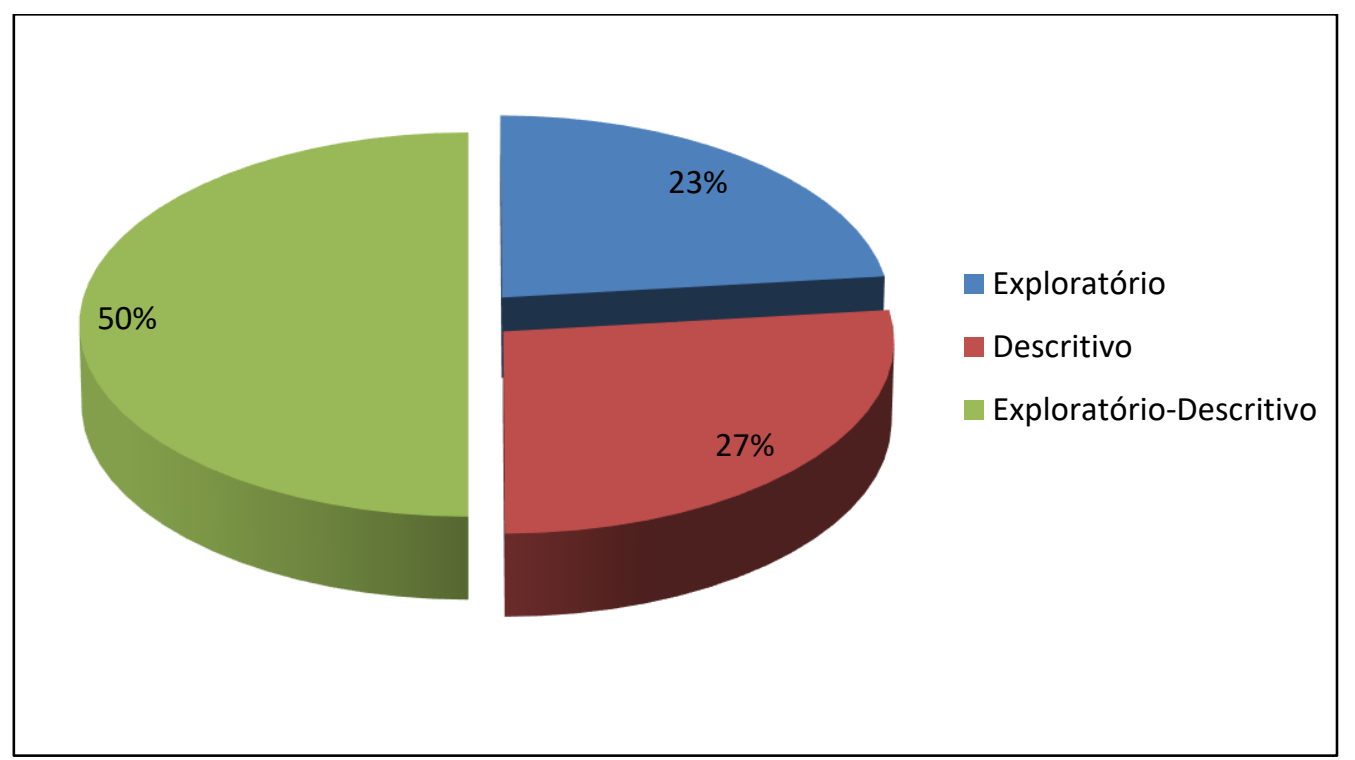

Fonte: dados da pesquisa.

Ocorreu uma porcentagem quase igualitária entre os artigos que eram apenas exploratórios e os outros artigos que apresentaram apenas o objetivo descritivo, totalizando $50 \%$ do total de artigos analisados. Já os que contemplam ambos os métodos (exploratório e descritivo) são no total de 28 artigos, representando os outros $50 \%$. Há tendências cada vez mais frequentes da utilização de ambos os objetivos, pelo fato de abrangerem melhor a amostra das pesquisas. Segundo Gil (2002) a explicação para isso é que algumas pesquisas descritivas de acordo com seus objetivos servem mais para abranger uma nova visão do problema, e isso acaba aproximando elas das pesquisas exploratórias.

A razão pela qual o objetivo exploratório esteve presente, sozinho e em conjunto com o descritivo pode ser explicada pelo fato de que esse método busca uma familiaridade maior com o objetivo de pesquisa e está presente de acordo com Gil (2002) geralmente em pesquisas bibliográficas e estudos de caso, que também foi um dos procedimentos técnicos mais presentes dos artigos analisados. 
Na tabela 6 a seguir, são evidenciados os procedimentos mais identificados nos artigos, é válido salientar que em alguns artigos foi identificado o uso de mais de um procedimento, sendo essa a razão de a soma total dos artigos da tabela ultrapassar o tamanho da amostra original.

Tabela 2 - Procedimento Técnico

$\left.\begin{array}{cc}\hline \text { Procedimento Técnico } & \text { Quantidade de artigos } \\ \hline \text { Bibliográfico } & 12 \\ \text { Documental } & 16 \\ \text { Levantamento } & 6 \\ \text { (questionário; formulário, } \\ \text { entrevista) }\end{array}\right)$

Fonte: dados da pesquisa.

Os artigos que continham apenas um procedimento técnico geralmente eram Estudos de Campo ou apenas Estudos de Caso, o que pode se explicar pelo fato de que ambas as técnicas exigem maior tempo e dedicação do pesquisador. De acordo com Gil (2002) tais técnicas consistem em estudo aprofundado e observação exaustiva do objeto que está sendo estudado. São portanto pesquisas que exigem mais tempomas que são em sua visão geral mais completas, pois exigem maior interação e percepção da amostra da pesquisa.

Já pesquisas que utilizaram 2 ou mais procedimentos técnicos foram as de técnicas bibliográfica, documental e levantamento (questionário; formulário, entrevista), que na maioria dos casos acompanhavam outras técnicas nos estudos. A respeito da técnica bibliográfica Gil (2002) diz:

Enquanto a pesquisa bibliográfica se utiliza fundamentalmente das contribuições dos diversos autores sobre determinado assunto, a pesquisa documental vale-se de materiais que não recebem ainda um tratamento analítico, ou que ainda podem ser reelaborados de acordo com os objetos da pesquisa. (GIL, 2002, p. 45)

O motivo da grande utilização das pesquisas documentais atreladas as outras fontes de coleta de dados, pode ser explicitado quando Gil (2002) explana que os documentos são uma fonte rica e estável de dados, e o custo desse tipo de pesquisa é baixo, requer apenas a disponibilidade de tempo do pesquisador para analisar tais documentos, são fontes exatas tornando-se "a mais importante fonte de dados em qualquer pesquisa de natureza histórica". 
A técnica de Levantamento abrangendo questionários; formulários e entrevistas também foi outra técnica bastante utilizada pelo fato de possibilitar informações gerais da população referente ao problema estudado. "São extremamente úteis, pois proporcionam informações gerais acerca das populações, que são indispensáveis em boa parte das investigações sociais". (GIL, 2002, p. 51)

A tabela a seguir mostra os principais públicos-alvo das coletas de dados.

Tabela 3 - Público-Alvo das Coletadas de Dados

\begin{tabular}{lc}
\hline \multicolumn{1}{c}{ Público-alvo das coletadas de dados } & Artigos \\
\hline Gerentes/gestores/posição de chefia & $60,7 \%$ \\
Trabalhadores/funcionários/Professores & $21,4 \%$ \\
Discentes de pós ou graduação & $7,14 \%$ \\
Pessoas com deficiência (PcD) & $3,57 \%$ \\
Outros não identificados & $7,14 \%$ \\
\hline
\end{tabular}

Fonte: dados da pesquisa.

É perceptível que o alvo das coletas de dados são as pessoas que detêm algum tipo de posição de chefia/liderança nas organizações, ocorrendo em mais de 60\% dos artigos analisados. Em segundo lugar o foco são os trabalhadores funcionários e professores seguido dos alunos de pós-graduação. Na sequência as pessoas com deficiência são registradas em 3,57 dos casos.

\subsection{ABORDAGENS TEMÁTICAS}

Para melhor compreensão das abordagens temáticas encontradas nos artigos foram elaborados 10 grupos de artigos com suas determinadas abrangências, que são: Inovação; Visão Baseada em Recursos (VBR); Liderança; Gestão por Competências (GPC) e Competências Gerenciais; Aprendizagem Organizacional e Desenvolvimento de Competências; Internacionalização e Competências Interculturais; Competências dos trabalhadores; pessoas com deficiência (Pcd) ; Área acadêmica; Competências individuais e organizacionais. O quadro 1 a seguir traz um resumo de cada um desses grupos, suas principais características e a quantidade de artigos contemplados.

Por esse quadro entendemos que o tema competências foi trabalhado de diversas maneiras, resultando nas abordagens apresentadas, o que dependia apenas de qual seria a finalidade da pesquisa. Percebeu-se que mesmo que se tenha apresentado 10 grupos de 
abordagens separadamente, elas não deixam de se relacionar uma com a outra. Como exemplo cita-se as abordagens de Internacionalização e Desenvolvimento de competências, posto que lidar com pessoas de localidades e culturas diferentes é uma característica inovadora dentro das organizações que pode aprimorar o desenvolvimento de competências e estimular a aprendizagem organizacional. 
Quadro 1 - Descrição Sintética das Abordagens Temáticas

\begin{tabular}{|c|c|c|c|}
\hline ABORDAGENS & DESCRIÇÃO SINTÉTICA DAS ABORDAGENS TEMÁTICAS & $\begin{array}{c}\text { COMPETÊNCIAS CITADAS NAS } \\
\text { ABORDAGENS } \\
\end{array}$ & $\begin{array}{l}\text { QTD DE } \\
\text { ARTIGOS }\end{array}$ \\
\hline Inovação & $\begin{array}{l}\text { Capacidade do indivíduo de identificar novas oportunidades. Produtos que } \\
\text { necessitavam de novas competências para serem criados. Utilização de fontes } \\
\text { inovadoras de recursos internos e também externos para a estratégia organizacional. }\end{array}$ & $\begin{array}{l}\text { Competências empreendedoras e competências } \\
\text { para inovação. }\end{array}$ & 4 \\
\hline Visão Baseada em Recursos & $\begin{array}{l}\text { Habilidades individuais e organizacionais como recursos. Utilização de recursos } \\
\text { internos como principal para a vantagem competitiva. Necessidade de } \\
\text { competências para utilização de recursos essenciais da organização. }\end{array}$ & $\begin{array}{l}\text { Competências e habilidades para utilização dos } \\
\text { recursos essenciais da organização. }\end{array}$ & 5 \\
\hline Liderança & $\begin{array}{l}\text { Competências de pessoas que chefiavam equipes. Necessidade de relacionamento } \\
\text { com pessoas externas além das internas da organização. }\end{array}$ & $\begin{array}{l}\text { Competências de liderança. Capacidades de } \\
\text { pessoas que estão à frente de equipe ou chefia. }\end{array}$ & 4 \\
\hline $\begin{array}{l}\text { Gestão por Competências } \\
\text { (GPC) e Competências } \\
\text { Gerenciais }\end{array}$ & $\begin{array}{l}\text { Adaptação das gestões atuais aos novos perfis gerenciais. Maior flexibilização para } \\
\text { mudança do modelo habitual de gestão. Identificação de competências gerenciais } \\
\text { que abrangem fatores e culturas externas da organização. }\end{array}$ & $\begin{array}{l}\text { Competências gerenciais para relacionamento } \\
\text { externo. Competências interculturais. }\end{array}$ & 12 \\
\hline $\begin{array}{l}\text { Aprendizagem Organizacional } \\
\text { e Desenvolvimento de } \\
\text { competências }\end{array}$ & $\begin{array}{l}\text { Desenvolvimento de competências em filias de acordo com seu ambiente externo e } \\
\text { não com o da matriz. Análises de necessidades de treinamento em longo prazo que } \\
\text { visam desejos futuros da organização. }\end{array}$ & $\begin{array}{l}\text { Competências coletivas, humanas, societais, e de } \\
\text { lidar com os impactos sociais e ambientais. }\end{array}$ & 6 \\
\hline $\begin{array}{c}\text { Internacionalização e } \\
\text { Competências Interculturais }\end{array}$ & $\begin{array}{l}\text { Adaptação ao mercado, clientes e culturas externas, diferentes. Competências que } \\
\text { abrangem a multiculturalidade. }\end{array}$ & $\begin{array}{l}\text { Competências que abrangem a multiculturalidade. } \\
\text { Competências internacionais. }\end{array}$ & 4 \\
\hline $\begin{array}{l}\text { Competências dos } \\
\text { trabalhadores }\end{array}$ & $\begin{array}{l}\text { Necessidade de maior identificação do empregado para com o trabalho, ir além de } \\
\text { concepções exploradoras. Relação menos hierárquica. }\end{array}$ & $\begin{array}{l}\text { Competências dos trabalhadores, técnicas, } \\
\text { transversais e morais. }\end{array}$ & 3 \\
\hline $\begin{array}{l}\text { Pessoas com deficiências } \\
\text { (PcDs) }\end{array}$ & $\begin{array}{l}\text { Competências desenvolvidas pelos PcDs e pessoas que convivem com eles na } \\
\text { organização. Competências que favorecem a inclusão e diversidade. }\end{array}$ & $\begin{array}{l}\text { Competências que favorecem a inclusão. } \\
\text { Competências para a diversidade. }\end{array}$ & 2 \\
\hline Área acadêmica & $\begin{array}{l}\text { Necessidade de trabalhar competências nos cursos superiores. Exigência da } \\
\text { concepção prática em conjunto com a teórica nas salas de aula. Competências na } \\
\text { formação dos docentes e discentes. Competências empreendedoras e gerenciais dos } \\
\text { alunos e professores. }\end{array}$ & $\begin{array}{c}\text { Competências na formação dos docentes e } \\
\text { discentes para melhor adequação dos futuros } \\
\text { formandos ao mundo do trabalho. Competências } \\
\text { empreendedoras e gerenciais trabalhadas nos } \\
\text { cursos superiores. }\end{array}$ & 12 \\
\hline $\begin{array}{l}\text { Competências individuais e } \\
\text { organizacionais }\end{array}$ & $\begin{array}{l}\text { Compartilhamento de competências individuais e interação entre grupos que facilita } \\
\text { a geração de resultados. Competências como conceito diferenciado de qualificação. } \\
\text { Integração de conhecimento, habilidade e atitude. }\end{array}$ & $\begin{array}{c}\text { Competências de nível individual e } \\
\text { organizacional. Integração de conhecimento, } \\
\text { habilidade e atitude. Competências profissionais e } \\
\text { coletivas }\end{array}$ & 4 \\
\hline
\end{tabular}

Fonte: dados da pesquisa. 
$\mathrm{Na}$ descrição do grupo relacionado às pessoas com deficiência notou-se que se faz necessário o desenvolvimento de competências voltadas para inclusão e diversidade, ou seja, lidar com pessoas que possuem necessidades diferentes daquelas consideradas habituais pela maioria. Em grande parte das vezes o desenvolvimento de competências ocorre na educação dos futuros profissionais que atuarão no mercado de trabalho, ou seja, os alunos de ensino superior. Assim parte-se para a ideia do grupo relacionado a área acadêmica, nele a maioria dos artigos trazem conclusões de que se precisa trabalhar da melhor forma possível o tema competências dentro das salas de aula e também junto aos docentes de forma a atualizá-los, tornando-os devidamente capacitados para lecionar matérias novas trazidas pela necessidade de desenvolver futuros profissionais cada vez mais inovadores e competentes, capazes de lidar da melhor forma possível com as mudanças encontradas no mundo do trabalho.

\section{CONCLUSÃO}

Pode-se afirmar que a pesquisa atingiu seus objetivos ao analisar as características dos perfis profissionais dos autores, bem como ao descrever as concepções e ferramentas metodológicas empregadas nas pesquisas e por fim elencar as principais abordagens temáticas dos artigos sobre competências entre 2008 e 2014.

$\mathrm{O}$ artigo revela que uma grande quantidade de autores apresentam alguma qualificação em Administração (47,29\% do total), porém, existindo também outras áreas profissionais envolvidas, não se resumindo apenas aos administradores. Foram encontrados diferentes áreas de graduação do currículo dos autores, do que se pode inferir que dependendo de como o tema 'competência' é abordado o mesmo pode ser trabalhado em diferentes áreas de conhecimento e a partir das mais variadas perspectivas.

Ainda sobre o perfil dos autores destaca-se o dado de que $68 \%$ é composta por doutores, em $64,86 \%$ dos casos os pesquisadores eram professores e em $61 \%$ dos casos os artigos foram produzidos via universidades das regiões sul e sudeste do Brasil, o que se explica pelo fato de nessas regiões se concentrarem boa parte das instituições mais tradicionais de ensino superior do país.

Na maioria dos casos as pesquisas apresentavam cunho qualitativo, com o emprego das técnicas dos estudos bibliográficos, documentais e ainda a aplicação de estudos de caso ou pesquisas de campo, dadas tais características pode-se afirmar que os estudos carregam uma forte influência dos aspectos subjetivo e teóricos. Em quase em todas as pesquisas os objetivos se resumiam a analisar, descrever ou identificar competências em um 
determinado público-alvo. As populações das amostras eram geralmente pessoas que estavam em alguma posição de chefia (60,7\% dos casos), poucos sendo os públicos-alvo que estavam no nível mais baixo da hierarquia organizacional, ou que estavam longe do âmbito corporativo.

Quanto às limitações do trabalho e sugestões para pesquisas futuras, pode-se considerar que seria mais interessante a utilização de uma amostra com mais bases de dados para que haja mais possiblidades de resultados e também a identificação novas abordagens temáticas. É interessante que haja mais estudos práticos, aplicados ao campo das competências e que os estudos saiam apenas da concepção de "analisar, identificar e descrever" competências passando para suas aplicações em projetos, estudos e modelos que caminhem para a criação e desenvolvimento de novas competências que se adequem as constantes mudanças encontradas nos mundos profissional e acadêmico.

\section{REFERÊNCIAS}

BRANDÃO. Gestão por competências em organizações de governo. Brasília: Enap, 2005.

DUTRA, Joel Souza. Competências: Conceitos e instrumentos para a gestão de Pessoas na empresa Moderna. São Paulo: Ed. Atlas. 2004.

DRUCKER, Peter. Desafios gerenciais para o século XXI. São Paulo: Pioneira, 1999.

FILHO, R. O. O. Competências essenciais norteadoras para o perfil do gestor estratégico em instituições de ensino superior, 2013.

Fleury, M. T.; Fleury, A. Construindo o Conceito de Competência. Revista de Administração Contemporânea, São Paulo, ed esp., v. 5, p. 183-196, dez. 2001.

FLEURY, M. T. ; FLEURY, A. Alinhando Estratégias e Competências. 2004.

FLEURY, A.; FLEURY, M. T. Estratégias competitivas e competências essenciais: perspectivas para a internacionalização da indústria no Brasil. Revista Gestão e Produção, v. 10, n. 2, p. 129-144, ago. 2003.

GIL, A. C. Como elaborar projetos de pesquisa. 4. ed. São Paulo: Atlas, 2002.

HAMEL, Gary; PRAHALAD, C. K. Competindo pelo futuro. Rio de Janeiro: Campus, 1995.

ISAMBERT-JAMATI, V.. O apelo à noção de competência na revista 1'orientation scolaire et professionelle - da sua criação aos dias de hoje. In ROPÉ, F. \& TANGUY, L. 
(orgs.). Saberes e competência: o uso de tais noções na escola e na empresa. Campinas-SP: Papirus, 1997.

KUARK, F.; MANHÃES, F, C.; MEDEIROS, C. H. Metodologia da pesquisa: guia prátic. Itabuna: Via Litterarum, 2010. 88p.

MOURA, M. C.; BITENCOURT, C. C. A Articulação entre estratégia, desenvolvimento de competências e Aprendizagem: da Teoria à Realidade organizacional. Anpad, p. 2, 2004.

MILLS, J.; PLATTS, K.; BOURNE, M.; RICHARDS, H. Strategy ahd performance: compenting through competences. Cambridge: Cambridge University Press, 2002.

PORTER, M. What is strategy? Harvard Business Review, v. 74, n. 6, p. 61-78, 1996.

PRAHALAD, C. K.; HAMEL, G. The core competence of the corporation. Harvard Business Review, Boston, p. 79-91, May/Jun. 1990.

PRAHALAD, C.K , HAMEL, Gary. "A Competência Essencial da Corporação". In: Montgomery, Cynthia A. e Michael Porter (org): A busca da vantagem competitiva. Tradução de Bazan Tecnologia e Lingüística. Rio de Janeiro: Campus, 1998.

SILVA, V, K. Diferença entre pesquisa qualitativva e quantitativa: Pibic Junior Mato Grosso do Sul, 2011. Discponível em: http://programapibicjr2010.blogspot.com.br/2011/04/ diferenca-entre-pesquisa-qualitativa-e.html. Acesso em: 20 nov. 2011.

ZARIFIAN, Philipe. Objetivo competência: por uma nova lógica. Trad. Maria Helena C.V Trylinski, São Paulo, Atlas, 2001. 